\title{
Los disputados sentidos del lugar. El deporte en la configuración del espacio rural
}

The disputed senses of the place. The sport in the configuration of the rural space

\author{
David Moscoso \\ Consejo Superior de Investigaciones Científicas (ESPAÑA) \\ dmoscoso@iesa.csic.es
}

Recibido: 22.02 .2010

Aceptado: 23.03.2011

\section{RESUMEN}

Lo rural es un concepto en continuo proceso de redefinición. A ello ha contribuido en las últimas décadas lo que algunos denominan por Reestructuración Rural, es decir, un proceso global que consiste, a su vez, en un conjunto de dinámicas de transformación de los usos materiales y los significados de valor atribuidos al espacio rural. Este proceso se caracteriza por promover la diversificación de las actividades económicas y la introducción de un nuevo orden territorial en este espacio. Nosotros proponemos desvelar algunos de los elementos que toman partida en el proceso de la reestructuración rural en el caso de Andalucía. Para ello, se ha estudiado una actividad, los deportes de naturaleza y el turismo activo, de escasa trascendencia pública, pero muy relevante para interpretar la pugna mantenida entre distintos grupos por la apropiación simbólica y material del espacio rural, así como otros problemas más generales sobre la ordenación del territorio. 


\title{
PALABRAS CLAVE
}

Sociología; Territorio; Desarrollo Rural; Deportes de Naturaleza.

\begin{abstract}
The rural is a concept continually being redefined. In recent decades what some have referred to as rural restructuring has contributed to this. This restructuring is a comprehensive process which consists in a series of dynamics transforming the material uses and the symbolic meanings attributed to rural space and is based on fostering the diversification of economic activities and the introduction of new regional planning strategies in rural areas. In this article we will analyze some of the elements that are a part of the process of rural restructuring taking place in Andalusia. To do this we have focused on a single area of activity, nature sports and active tourism, of relative social significance today, and of importance in understanding the existing conflicts between different groups for the symbolic and material appropriation of rural space, as well as other broader problems related to regional planning.
\end{abstract}

\section{KEYWORDS}

Sociology; Territory; Rural Development; Nature Sports.

\section{INTRODUCCIÓN}

El trabajo que se presenta en estas páginas analiza algunas cuestiones abordadas en la tesis doctoral titulada «Reestructuración Rural. Análisis de las prácticas deportivas de naturaleza en el desarrollo rural de Andalucía» (Moscoso, 2010). El objetivo de ésta consistió en analizar el proceso de reestructuración rural en esta región, centrando la atención en la difusión de los deportes de naturaleza como observatorio de dicho proceso. En este marco, el nudo gordiano que ha tratado de despejarse es el siguiente: ¿Cómo se explica el proceso por el cual el espacio rural, que históricamente no tenía más función e interés para la sociedad urbano-industrial que el de la provisión de materias primas y alimentos, se haya convertido en nuestros días en un lugar de enorme atractivo para su uso lúdico, recreativo y deportivo? Y, con ello, ¿cómo se articulan las estrategias y los intereses de las poblaciones que en estas zonas residen con las de los nuevos colonizadores (neorrurales, empresarios, técnicos, deportistas y turistas), ya sea en el sentido residencial o ya lo sea en el sentido lúdico-recreativo?

Este objetivo se enmarca en una problemática más general sobre la nueva definición del espacio rural en los países occidentales, como consecuencia de la 
pérdida de importancia del sector agrario en la funcionalidad de este espacio, las tendencias de cambio cultural experimentadas en las últimas décadas y el debilitamiento de la centralidad urbana en las preferencias residenciales y recreativas de los ciudadanos (Rivera, 2008). En este marco, conocer el desarrollo de nuevas actividades económicas y culturales en el espacio rural, ejemplificado aquí en los deportes de naturaleza, adquiere un especial interés. Esto es así porque representa un buen indicador para mostrar cómo se ha desentrañado este proceso de reestructuración, tal como defienden Roberts y Hall (2001), y qué implicaciones ha supuesto para el medio rural andaluz.

Una de las principales dificultades con las que se ha topado este trabajo ha sido carecer de referencias sobre el fenómeno estudiado. En el análisis de los procesos de reestructuración rural, la sociología ha puesto un especial énfasis en los cambios socioeconómicos y en las nuevas pautas demográficas y residenciales experimentados en este espacio, si bien ha mostrado un escaso interés por los aspectos relacionados con el uso recreativo y la nueva ordenación del territorio. Un caso excepcional en este sentido es la compilación de trabajos coordinada por Roberts y Hall (2001) y la investigación realizada por González Fernández (2002).

La difusión de los deportes de naturaleza se ha presentado como un escenario privilegiado para esta tarea, porque nos ha ayudado a comprender mejor un proceso de cambio social y económico del que, pese a su inmenso calado, existe tanto desconocimiento. El proceso de la reestructuración rural, como se sabe, es el resultado de un conjunto de cambios económicos y políticos producidos a nivel internacional, en virtud de los cuales la comunidad internacional ha adoptado una serie de medidas dirigidas a transformar la funcionalidad de los territorios rurales. Este hecho quizá haya conducido con frecuencia, entre los especialistas, a centrar la atención en los mecanismos comunes de intervención de la UE y, especialmente, en el impacto de sus programas de desarrollo rural. De esta forma, se ha tendido a ignorar el interés que tiene para la clarificación de este proceso el análisis de las estrategias colectivas entre aquellos grupos sociales no representados entre los sectores profesionales tradicionales, pero que igualmente participan en la construcción de la ruralidad. Tal limitación puede haber incurrido en el pasado en algunos desatinos durante la aplicación de los mecanismos empleados en el desarrollo rural.

El estudio realizado nos ha mostrado que los deportes de naturaleza sirven para conocer problemas más generales sobre la ordenación del territorio. En este sentido, el estudio en el que se basa el presente artículo ha servido para revelar algunas situaciones ignoradas anteriormente, como la pugna mantenida entre distintos grupos por la apropiación simbólica y material de este espacio. El sometimiento del espacio rural a este proceso y a otras formas paralelas de intervención económica y política (como los planes y programas regionales de protección y conservación de los espacios naturales, la recalificación de suelos rurales para la construcción de urbanizaciones y las grandes explotaciones agrícolas y ganaderas), revela un escenario de enorme complejidad, debido a las nu- 
merosas concepciones e intereses que entran en juego en la configuración de las imágenes y las reglas que definen el uso de ese espacio.

\section{METODOLOGÍA}

La investigación se ha desarrollado en varias fases que han cubierto tres años de trabajo, desde comienzos de 2005 a fines de 2007 (ver tabla 1). Durante una primera fase, el trabajo de investigación consistió en la revisión de los documentos de referencia que abordan el análisis de los procesos de cambio experimentados en el medio rural en Europa en las últimas décadas y, en específico, la difusión de los deportes de naturaleza en el marco de esas transformaciones. El contexto de este análisis se circunscribió a los trabajos de algunos miembros del conocido Rural Economy and Society Study Group, con vocación multidisciplinar y con gran reconocimiento internacional, y también los trabajos de algunos de los profesores que conforman el Seminario de Estudios Rurales de la Universidad Nacional de Educación a Distancia (UNED).

Tabla 1. Cronograma de trabajo de la tesis doctoral

\begin{tabular}{|c|c|c|c|c|c|c|c|c|c|c|c|c|}
\hline & ENE & FEB & MAR & ABR & MAY & JUN & JUL & AGO & SEP & OCT & NOV & DIC \\
\hline \multirow[t]{2}{*}{2005} & & & & & & & & & & & & \\
\hline & \multicolumn{12}{|c|}{ Revisión bibliográfica y recopilación documental } \\
\hline & & & & & & & & & & & & \\
\hline \multirow{3}{*}{2006} & \multicolumn{6}{|c|}{ Explotación de datos secundarios } & & & & & & \\
\hline & & & & & & \multirow{2}{*}{\multicolumn{7}{|c|}{ Preparación y realización del trabajo de campo }} \\
\hline & & & & & & & & & & & & \\
\hline \multirow{6}{*}{2007} & \multirow{2}{*}{\multicolumn{4}{|c|}{$\begin{array}{c}\text { Culminación del trabajo } \\
\text { de campo }\end{array}$}} & & & & & & & & \\
\hline & & & & & & & & & & & & \\
\hline & \multirow{2}{*}{\multicolumn{6}{|c|}{$\begin{array}{l}\text { Análisis de la información } \\
\text { del trabajo de campo }\end{array}$}} & & & & & & \\
\hline & & & & & & & & & & & & \\
\hline & & & \multicolumn{10}{|c|}{ Contrastación de hipótesis y redacción de la tesis } \\
\hline & & & & & & & & & & & & \\
\hline
\end{tabular}

En una segunda fase, la investigación se centró en el análisis de datos secundarios, tanto de naturaleza empírica (se explotaron datos parciales obtenidos en distintos estudios y encuestas sobre sociedad y desarrollo rural en Andalucía, como el Agrobarómetro y la Evaluación Intermedia de la Iniciativa Comunitaria Leader en Andalucía, realizados 2006 y 2007, respectivamente, por el IESACSIC, y también sobre hábitos deportivos, en concreto la Encuesta de Hábitos Deportivos de los Españoles llevada a cabo por el CIS en 2005); y datos de naturaleza estadística y administrativa (la Base de Datos de Acciones Leader en 
Andalucía, la Estadística sobre Uso de Infraestructuras de Espacios Naturales Protegidos de Andalucía, el Registro de Empresas y Productos Marca Parque Natural de Andalucía y, por último, el Registro de Turismo de Andalucía). Este análisis se realizó con el fin de explicar algunos de los interrogantes de la investigación y determinar las claves de la adecuada orientación del trabajo de campo en la última fase.

La tercera fase, que es la parte en la que se apoya este artículo, se realizó en 2007. Ésta sirvió para desarrollar un trabajo de campo propio, basado en una metodología de estudio de casos y el empleo de técnicas cualitativas.

En lo que concierne a la relevancia de este método, ésta se justifica en razón de las experiencias acumuladas en el ámbito de la sociología rural - sobre todo, en sus inicios y en los últimos años. Quizá la obra de Tönnies (1974), que pretendía demostrar la pérdida de valores comunitarios en las sociedades tradicionales, a medida que se imponía el modelo urbano-industrial, sea una de las primeras y más conocidas. También destacan las de Sorokin y Zimmerman (1929), Lewis (1949) y Pahl (1966), si bien hay una infinidad de trabajos en esta línea metodológica. Sin embargo, tras un periodo en el que el uso de este método se había encontrado muy limitado también en esta área de conocimiento, en los últimos años se ha dado una tendencia hacia su recuperación. A raíz de las orientaciones que tomaron las políticas de desarrollo rural en Europa desde inicios de los noventa, su empleo ha adquirido presencia, ya que programas como el Leader y el Proder han requerido grandes inversiones para su evaluación, y eso se ha hecho a escala territorial y de manera comparativa - fundamentalmente, inter-regional e inter-comarcal. En esta línea, ha de destacarse el trabajo de Pérez Yruela et. al. (2000: 30), donde se sostiene que «en las actuales circunstancias es importante la realización de estudios de casos para conocer mejor cuáles son los factores que condicionan el éxito o fracaso de los procesos de desarrollo rural».

No obstante lo anterior, en otros trabajos se ha denunciado que muchos de los estudios de casos sobre la sociedad rural - sobre todo, en el ámbito del desarrollo rural - se limitan al análisis del crecimiento del empleo o de la actividad económica para establecer resultados. "Valorar en estos casos el desarrollo en términos sólo de crecimiento puede ser una visión estrecha a la hora de apreciar el sentido del cambio socioeconómico que puede estar teniendo lugar en ellas» (Ibid.: 35). De ahí que haya quien considere (Oliva y Camarero, 2003: 33) que «la sociedad, su transformación, constituye el fin último del desarrollo, pero raramente en los diagnósticos alcanza otra consideración que la mera cuantificación de recursos humanos o, lo que es peor, es comúnmente destacada como el gran freno del mismo».

En ese contexto, el trabajo de campo de esta investigación se ha decidido por el empleo del grupo de discusión y la entrevista en profundidad como técnicas de recogida de información, pues éstas resultan más útiles que otras para el esclarecimiento de aspectos hasta ahora poco analizados acerca de los individuos y los grupos que se relacionan en los escenarios de la ruralidad. En efecto, con 
ambas técnicas se pretendía acceder a los discursos construidos entre los diferentes grupos de actores y, con ello, a las representaciones colectivas (sistemas de normas y valores, imágenes asociadas a instituciones, colectivos u objetos, tópicos, discursos estereotipados, etc.) sobre la ruralidad y, en concreto, sobre la práctica de los deportes de naturaleza como un rasgo del nuevo imaginario de la ruralidad. Así, se intentaba dibujar los paisajes sociales, los lugares, los espacios (que aquí se entienden como constructos sociales sobre los que se generan estrategias relacionales de actitudes y comportamientos), en los que tienen lugar las interacciones, la comunicación entre los actores que forman parte y recrean, o simplemente actúan como espectadores, del fenómeno estudiado en las distintas zonas seleccionadas.

Dicha labor se ha logrado por medio del análisis de las metáforas y los sentidos de las interacciones (a través de la práctica de los deportes de naturaleza, y a través de los estilos de vida y las representaciones de los lugares de quienes los practican, y de otro elenco de actores sociales, políticos y económicos) que se identifican en los discursos de los intervinientes en las entrevistas y los grupos de discusión. De todo ello se extrae finalmente una visión de conjunto del contexto en que tienen lugar las representaciones sociales, a saber: un contexto de cambio cultural (de crisis del modelo urbano-industrial) y de reestructuración económica y política de la ruralidad; un contexto que se caracteriza por nuevos encuentros y desencuentros, nuevas relaciones conflictuales y nuevas estrategias de articulación social en el medio rural.

Con todo, el trabajo de campo tenía como objetivo la comprensión de aquellos interrogantes más específicos que se formulan en las hipótesis de esta investigación, a saber:

1) Entre los principales factores que influyen en la difusión de los deportes de naturaleza destaca especialmente el proceso de la reestructuración rural, ya que éste ha «puesto en valor» las propiedades paisajísticas y patrimoniales del espacio rural e impulsado distintos tipos de actividades de ocio y tiempo libre.

2) Otro de los factores que explican la divulgación de estos deportes es el paso de una economía basada en la «producción» y el «consumo» a lo que podría entenderse por economías de signos y espacios. La revalorización de estos espacios y, con ello, el desarrollo de actividades de ocio y tiempo libre responden a: a) la necesidad de encontrar nuevos yacimientos de empleo entre la población de pequeños y medianos municipios, frenando así el trasvase de población del campo a las ya congestionadas ciudades; b) el suministro de oportunidades de ocio y recreación entre la población urbana que, saturada a niveles psico-cognitivos, necesita disfrutar de su tiempo libre desarrollando actividades con las que puedan distanciarse de sus entornos próximos; y c) la continuidad de la economía de mercado mediante la comercialización de actividades y lugares que, en forma de emociones y experiencias, satisfacen esas necesidades del hombre derivadas de la saturación por el modelo de vida urbano-industrial.

3) En torno a los deportes de naturaleza que se difunden en el marco de la reestructuración rural se representa una nueva forma de organización social, po- 
lítica y económica, y de planificación del territorio. Esta nueva situación da pie a una nueva realidad en el denominado hasta ahora como espacio rural. En primer lugar, aparecen nuevos actores y, con ellos, nuevos roles sociales y económicos, que producen nuevas interacciones sociales. En segundo lugar, esa situación de diversificación de los roles sociales y económicos genera, a su vez, un incremento de las tensiones entre los distintos actores, ya que los intereses y las percepciones sobre la ordenación y el aprovechamiento de los recursos locales también adquieren posiciones cada vez más plurales.

4) En este nuevo escenario que caracteriza al espacio rural, da la impresión de que lo rural y lo urbano se funden, se asemejan entre sí, en el predominio de los valores culturales, en el tipo de actividades económicas (eminentemente terciarizadas), en las pautas de consumo y, en definitiva, en los modelos de organización social. En este nuevo escenario cabe preguntarse si hoy aún es posible seguir hablando de lo rural, de la ruralidad o de las ruralidades, pues parece que el término rural hace referencia a una realidad que ya no se caracteriza por unos rasgos tangibles (como el espacio físico, las actividades económicas y la cultura), sino por la construcción simbólica de una imagen sobre algo que no existe más allá de nuestras conciencias.

La selección de la muestra responde a un objetivo muy específico: llenar el vacío existente sobre la explicación de los factores que influyen en la emergencia de los deportes de naturaleza en el medio rural y, a partir de ello, explicar el cambio al que se han visto y aún siguen encontrándose abocadas las poblaciones y los espacios calificados tradicionalmente como rurales. Ésta se ha delimitado de acuerdo con los siguientes criterios:

a) Las características de los actores. Dado que se partía del convencimiento de que en el espacio rural conviven una pluralidad de actores con perfiles sociodemográficos, intereses y actividades heterogéneas, nos interesaba reconstruir la percepción compartida por esos distintos actores (con sus distintas representaciones y discursos) sobre los deportes de naturaleza, obteniendo así, previsiblemente, una representación amplia y heterogénea sobre éstos. Por lo tanto, nos interesaba que la muestra de la población estudiada estuviese representada por personas que cumplieran con los siguientes rasgos:

- El carácter residente y foráneo de los entrevistados. La consideración de este criterio se explica por el hecho de que, en los últimos años, los actores que entran en juego en la planificación y los temas de interés del espacio rural son personas tanto residentes en estos espacios como foráneas. Además, la elección de una actividad como los deportes de naturaleza, donde la mayor parte de sus practicantes y los empresarios que prestan estos servicios proceden de las grandes y medianas ciudades, implica necesariamente contemplar este criterio.

- La condición de practicante y no practicante de estos deportes. La razón de este criterio de selección radica en que la difusión de estos deportes no se debe en exclusiva a los propios practicantes, sino también a una serie 
de actores vinculados al desarrollo rural, el mundo de la empresa, el sistema deportivo, etc.

- Entre los deportistas, contemplamos distintos perfiles, según el tipo de prácticas deportivas que se realizan y la forma como se llevan a cabo. Nosotros hemos optado por el tipo de disciplinas más practicadas (deportes de tierra, o sea, senderismo, escalada...), entre los dos perfiles de practicantes más habituales.

- Por último, las ocupaciones de los actores. Este elemento nos ha permitido contrastar el tipo de discurso que los diferentes actores tienen construido respecto a la percepción sobre los deportes de naturaleza y su dfusión en el medio rural.

b) Las características del territorio. La adopción de este criterio se justifica por el hecho de que igualmente se partía de la hipótesis de que existen distintos escenarios relativos a la difusión de los deportes de naturaleza en el marco del desarrollo rural. Esta circunstancia se explicaría en razón de que exista o no un proyecto territorial compartido por los actores económicos y políticos locales basado en el empleo de los deportes de naturaleza y el turismo activo como una actividad estratégica para el desarrollo comarcal. A su vez, también estaría determinado por la existencia de parques naturales en el entorno.

Con estos criterios, dado que se trata de un estudio eminentemente exploratorio, se han realizado tres grupos de discusión y ocho entrevistas individuales semiestructuradas, con el fin de obtener la información necesaria para componer las explicaciones respecto a las preguntas que nos planteamos en la investigación. En concreto, se realizó un grupo de discusión entre jóvenes emprendedores locales en la Sierra de Segura, a fin de conocer hasta qué punto surgía un discurso espontáneo sobre una actividad presumiblemente inexistente en el imaginario de esta población; un grupo de discusión entre los profesionales del sector allí donde efectivamente se ha producido un mayor desarrollo del turismo activo, o sea, en Sierra Nevada; un conjunto de entrevistas individuales en profundidad a distintos tipos de actores en la Subbética Cordobesa, como escenario intermedio, a fin de profundizar en aspectos específicos; y, por último, dos grupos de discusión con deportistas de naturaleza de distintos perfiles, uno en Córdoba y otro en Jaén. La estructura de esos grupos de discusión y entrevistas se detallan en las tablas 2 a 6 (ver anexo 1).

La población que ha participado en el estudio ha quedado delimitada por los siguientes perfiles: a) Gerentes y empleados vinculados al sector agroalimentario; b) trabajadores locales del sector público (fundamentalmente, profesores de educación física y trabajadores del SAS); c) gerentes y empleados de empresas de turismo activo, la hostelería y las asociaciones deportivas, incluyendo a guías de espacios naturales protegidos; d) deportistas y turistas de naturaleza, residentes en zonas urbanas, con distintos perfiles (de carácter más amateur y deportistas con mayor frecuencia de práctica); y e) personas vinculadas al sector organizativo de las actividades en la naturaleza (clubes y asociaciones deportivas). 
Según sus características sociodemográficas, las 26 personas participantes en los grupos de discusión y las entrevistas se distribuyen de la siguiente forma: aproximadamente, el $60 \%$ han sido hombres y el $40 \%$ mujeres, siendo prácticamente el 50\% jóvenes (25-35 años) y el otro 50\% adultos (36-55 años). El perfil formativo de los mismos es también irregular: en torno al $50 \%$ posee estudios universitarios de grado medio y superior (fundamentalmente, de agrónomos, empresariales y educación primaria) y la otra mitad posee estudios de grado medio no universitarios, es decir, de formación profesional ocupacional.

\section{MARCO DE REFERENCIA}

\subsection{Posmodernidad y posfordismo. Hacia una nueva configuración de la ruralidad}

En la actualidad, la nueva imagen de la ruralidad es el resultado de un doble proceso: la adopción de un nuevo modelo de economía (el posfordismo) y la emergencia de un nuevo sistema cultural (la posmodernidad). Lo más destacado de ese doble proceso en este ámbito de la realidad que estudiamos es la aparición de múltiples representaciones de la ruralidad. A esa imagen característica de la modernidad, por la que el sentido de la ruralidad era construido en base a la implantación de un sistema de valores de corte urbanocéntricos (lo rural como algo arcaico, como una fase de atraso en el proceso lógico del desarrollo, de la evolución de las sociedades), se sumará ahora un sinfín de imágenes construidas y reconstruidas, en función de los múltiples intereses y valores culturales que moran sobre las conciencias de los individuos en las sociedades modernas avanzadas.

Esta nueva situación quizá pueda explicarse por el hecho de que, en la posmodernidad, a diferencia de la modernidad - donde la realidad social era el resultado de una doble ideología enfrentada (la de la tradición, la de las sociedades premodernas, eminentemente agrícolas y estamentales, y la de la modernidad, la de las sociedades industriales, en las que además tendrá lugar el surgimiento de la sociedad civil) - , el proceso de construcción social adquiere una especial complejización, puesto que comienzan a imperar nuevos paradigmas de pensamiento (caracterizados por la reflexividad y el relativismo) y nuevos patrones de economía (la economía de ficción o posorganizada y globalizada), que contribuyen a flexibilizar y ampliar los campos de significado de los productos (objetos y servicios) que se consumen.

Esta afirmación nos impulsa a considerar otra idea que guarda especial relación con lo anterior: en la modernidad avanzada o posmodernidad todo se consume, todo es producto de un mercado - ya no de objetos sino de ideas - que impregna buena parte de las relaciones sociales. En la posmodernidad, el consumo - más bien, el posconsumo - lo irradia todo, incluso a la ruralidad, que se convierte en objeto de múltiples intereses sobre la base de diferentes usos económicos y sociales. 
En este nuevo contexto han aparecido una serie de posturas teóricas en el ámbito de la sociología rural cuya influencia ha sido determinante tanto para la comprensión de los cambios que afectan al espacio rural, cuanto para encauzar las políticas de desarrollo que tienen lugar en este espacio. La primera de estas posturas relevantes en los últimos años ha sido la ya citada «Reestructuración Rural», que aparece en el seno de un grupo de sociólogos (Marsden, Lowe, Whatmore y Murdoch) preocupados por encontrar claves para el análisis de los nuevos cambios que, ante la díada globalización/ localización, tienen lugar en el espacio rural, preocupación que expresaban con gran brillantez Marsden et al. (1990) hace casi dos décadas: «las áreas rurales, sus residentes y organizaciones se enfrentan en la actualidad a un rápido cambio social, económico y político. El balance entre producción, ocio, movilidad y desarrollo se reajusta en la medida que las actividades económicas se relocalizan. Igualmente los valores relativos a la vida y la participación en lo rural son objeto de cambio. Fuerzas políticas locales, nacionales e internacionales tienen una influencia directa sobre las áreas rurales».

La Reestructuración Rural propone, por tanto, en palabras de González Fernández (2002: 82), «una visión de lo rural compleja y globalizadora». Se parte, desde esta corriente, de la idea de que, ante los nuevos cambios por los que pasa el espacio rural, se produce una reestructuración del espacio, fundamentalmente de las actividades económicas $-\mathrm{y}$, puede decirse que, más que de las actividades económicas, de los roles que éstas desempeñan-, adquiriendo relevancia nuevos sectores (como el turismo, la repostería, la artesanía, la protección ambiental, etc.) en detrimento de actividades desarrolladas tradicionalmente (básicamente, la agricultura y la ganadería).

El inconveniente de este cuerpo teórico es que centra su atención en las actividades económicas, olvidando la importancia de lo sociocultural y sociopolítico. Por esta razón, otras corrientes más actuales, como por ejemplo el «Constructivismo» («Countryside»), de la que también forman parte autores del cuerpo de la «Reestructuración Rural», defienden la «aparición de un campo más diferenciado, debido al ensamblaje más complejo de elementos económicos, sociales y políticos. Estos elementos pueden estar presentes a escala local, regional, nacional e internacional» (Marsden et. al. 1993).

En esta corriente destaca la presencia de dos autores, John Urry y Keith Halfacree, quienes han dado un vuelco cualitativo al cuerpo teórico del «Constructivismo». Éstos han introducido elementos esenciales para la comprensión del espacio rural, de sus procesos de estructuración y cambio social. Comparten la importancia que sobre la determinación del espacio rural tiene la interdependencia entre lo económico, político y social, a escala global y local; es decir, parten del supuesto de que el espacio, que en este caso es rural, es producto de un proceso de construcción social, en el sentido de las teorizaciones de Berger y Luckmann (1984). Sin embargo, ellos van más allá de este presupuesto, en la medida que consideran que existe una preeminencia de lo cultural no identificada hasta ahora, a saber: lo cultural, que se consume, en forma de signos y significados, para construir realidades; realidades que a su vez determinan formas 
espaciales, diferentes formas de organización del espacio. Con ello dan un «vuelco cultural» a la interpretación de la realidad social. Pero, en este proceso de simbiosis entre los elementos económicos, sociales y políticos, y entre lo local y lo global, el consumo de signos es cada vez más personal, individual y, por tanto, los espacios sociales (los urbanos y también los rurales) son, cada vez más, productos resultantes de procesos de conflictos y negociaciones entre los diversos miembros y grupos sociales que conforman tales espacios.

De esta forma, «la interpretación que ofrece el enfoque constructivista hace aflorar el carácter intersubjetivo y sociopolítico de la categorización de determinadas partes del espacio como rurales y las pugnas reales y simbólicas que se producen en la definición global y local de éstas» (González Fernández, 2002:86).

\subsection{Los deportes de naturaleza como observatorio de la realidad social}

Hace tiempo que se asumió la importancia del deporte en nuestras sociedades, de ahí que siempre haya sido un objeto de preocupación sociológica. Algunos conocidos precursores de la sociología (Spencer, Weber, Simmel, Mead, Znanieki, Scheler, Elias, Bourdieu, Habermas...) se refirieron a esta actividad inspirados en diversas motivaciones (Moscoso, 2006). Y es que, en efecto, el deporte, aparte de constituir una actividad milenaria del ser humano (Blanchard y Chesca, 1986), es también un espacio de interacción que permite indagar en la naturaleza de las estructuras y los cambios sociales. Tal como señala Guay (1993), «el deporte está ampliamente abierto a un entorno que le da forma y del que es reflejo: es un microcosmos que remite a un macrocosmos, que es la cultura».

En lo que atañe específicamente a los deportes de naturaleza y aventura, éstos cuentan con otros atributos de especial interés para los propósitos de este trabajo, entre los que cabe destacar el que inspiren una visión del mundo diferencial, entre el pasado, presente y futuro, y también entre lo local y lo global; y, además, el que tengan un importante carácter simbólico y representacional. De ahí su interés como objeto de estudio, pues «constituye un importante «laboratorio» emocional, donde el individuo «aprende» $\mathrm{y}$ «experimenta» los «modelos etológicos y emocionales» que son considerados legítimos por su cultura» (Sánchez, 1997: 42). A este respecto, Feixa (1995: 39-40), siguiendo la tesis de Elias defendida en su obra The Quest for Excitement in Unexciting Societies, establece que, «en las sociedades industriales avanzadas, las ocasiones para un disfrute controlado de las emociones se crean y recrean sobre todo en las actividades recreativas de ocio». De tal forma que las actividades de ocio y, con ellas, este tipo de deportes al que nos referimos, se convierten en «actividades miméticas por su capacidad para trasponer las emociones de la vida real en una dimensión irreal, imaginaria [...] Como en el cine o los parques de atracciones, las actividades físicas de aventura en la naturaleza recrean aventuras miméticas mediante un escenario altamente estructurado, aunque parezca salvaje: el espa- 
cio y el tiempo están ordenados física y simbólicamente (rutas fluviales, zonas de aterrizaje, ritos minuciosamente organizados); el entorno social está gestionado por la institución promotora (empresa de servicios, monitores) y por el mismo grupo protagonista».

En la actualidad, con la consolidación de ciertos valores postmodernos, parece que todo ello se expresa con una mayor intensidad en uno de sus escenarios privilegiados: la naturaleza, un lugar caracterizado en su pasado por un profuso imaginario (en ocasiones sagrado, pero también ocupado por moradores sin alma, brujas, hechizadores, lobos y otros monstruos indescriptibles), un simbolismo que no escapa a nuevas expresiones en el presente. Por esa razón, todo lo que en este espacio se desarrolla adquiere una cierta connotación simbólica, máxime tras la emergencia de valores postmodernos, pero antes bien por el desarrollo económico durante la modernidad avanzada. Como arguye González Fernández (2002: 105), «la modernidad ha acabado por conquistar también las más altas cumbres. Ha puesto en valor el espacio montañoso [la naturaleza], lo ha convertido en «yacimiento» - real y metafórico- de recursos económicos. De ahí que las nuevas mitologías nos estén comenzando a hablar de la banalización, de la «prostitución» de unos lugares antes sagrados. Y de la necesidad de purificación - como paso previo a la «resacralización»- de la montaña, vista hoy como la quintaesencia de la naturaleza».

Con todo, los usos y prácticas deportivas de naturaleza se emplean aquí como un elemento con el que demostrar empíricamente las hipótesis planteadas, los cambios vividos como resultado del proceso de reestructuración rural y las consecuencias que de este proceso se han derivado para las realidades cotidianas en los territorios sujetos a su influencia. Y eso se debe a que el estudio de los deportes de naturaleza en el marco del desarrollo rural plasma esa atribución de significados, usos y recursos, señalada.

\section{RESULTADOS}

\subsection{El papel de la Reestructuración Rural en la transformación de la ruralidad}

La hipótesis general sobre la transformación de la imagen del espacio rural a través del proceso de la reestructuración ha sido confirmada mediante la influencia de este proceso en la difusión de los deportes de naturaleza. El papel de tales programas en la promoción de estos deportes explica la coincidencia entre, de un lado, el lenguaje y los temas de debate empleados en el seno de los organismos encargados de implementar actuaciones al respecto y, de otro lado, el discurso compartido por algunos de los actores analizados (empresarios de turismo activo, jóvenes emprendedores, etc.). En este sentido, la investigación ha revelado un carácter muy directivo entre esos actores, al atribuir una función esencialmente «material» a esta actividad, por la que se justificaba su promoción en 
virtud de una «pretendida diversificación de la economía rural» (una idea asociada al concepto de multifuncionalidad).

Desde esta posición, los deportes de naturaleza son considerados de forma análoga a la actividad turística, por lo que los criterios empleados para su promoción guardan una estrecha relación con los intereses, objetivos y preocupaciones propios de esta actividad; pero no del deporte (y, con él, de los deportistas) per se.

Empresaria1: Hay un montón de recursos endógenos que se pueden potenciar... muchísimos palos que todavía no se han tocado: el tema del turismo, el agroturismo, la agricultura y la ganadería ecológica, la alimentación ligada al turismo... o sea, tiene muchísimos valores. $Y$ tal vez el gran reto es profesionalizar todo esto... Llega mucha gente a hacer senderismo a esta zona, y que estaría dispuesta, porque son gente que tiene afinidad a la montaña, la naturaleza, y es afín también a la alimentación ecológica, y si, por ejemplo, en un restaurante de Siles hubiera un menú ecológico o que hubiese ya una tienda donde hubiese aceite ecológico o...

(Grupo de discusión. Jóvenes emprendedores rurales. Orcera (Jaén). Sierra de Segura).

\subsection{La influencia del cambio cultural en el nuevo imaginario rural}

La hipótesis general es complementada con otra hipótesis, cual es la relevancia que, en el marco de este proceso, tienen el cambio cultural y la economía de signos y espacios - una idea tratada por Urry (1995) en su obra Consuming Places. La relevancia de estos elementos estriba en que el proceso de reestructuración ha tratado de difundir una «nueva imagen de lo rural» coherente con los valores predominantes en la posmodernidad y consistente al tiempo en una nueva versión de la economía neoliberal (el mercado de signos y espacios). Nuestra investigación ha permitido constatar ambas relaciones a través de una imagen de la ruralidad basada en el disfrute (consumo) de una serie de actividades (servicios) vinculadas a la recreación y el tiempo libre (el turismo, los alojamientos rurales, la gastronomía local, la contemplación del paisaje, flora y fauna, y los deportes de naturaleza).

Empresario1: Lo que hacemos es entretener al visitante que viene al Parque Natural y Nacional de Sierra Nevada, mostrarle sus valores de diferentes maneras (a pie o en bicicleta o en esquí en invierno o escalando, en todo terreno también tenemos visitas guiadas al parque), y, bueno, sobre todo, lo que hacemos es dar a conocer los valores naturales y paisajísticos que tiene esta montaña, y culturales, por supuesto. Dentro de nuestra programación hay actividades que van enfocadas a conocer la cultura, los pueblos, la historia, la gastronomía, la forma de vida, y después pues otras actividades en la media y la alta montaña que están más a nivel cultural y paisajístico

(Grupo de discusión. Empresarios de Turismo Activo. Pampaneira (Granada). Sierra Nevada). 
De ahí que se observen diferencias substanciales en la visión de la lógica productiva entre estos empresarios de Sierra Nevada y la población de la Sierra de Segura, puesto que en la zona del Barranco de Poqueira de Sierra Nevada el sector ha experimentado un largo recorrido, hasta el punto de darse hoy lo que algunos autores califican por Dysneificación o Museificación de la ruralidad (Relph, 1976; Walter, 1998) y otros, en relación al turismo, por Ficcionalización del Mundo (Augé, 1998) o Simulación (Raffestin, 1995), algo asociado a esa idea defendida por Urry (1995) por la que los lugares son convertidos en objetos susceptibles de ser consumidos de forma masiva. Y es que esta «Dysneificación» o «Museificación» de la ruralidad es vista positivamente por los empresarios de esta zona de Sierra Nevada, por considerar que esto es, entre otras cosas, lo que atrae a los turistas a la Sierra.

Esta hipótesis resalta, en consecuencia, que la promoción de los deportes de naturaleza en el marco de la reestructuración rural se realiza específicamente desde esa pretendida diversificación de la economía rural y, por ende, con el carácter material que esta noción implica. Esta circunstancia explica el hecho de que no todos los grupos vinculados a estos deportes se encuentren identificados con la promoción que desde esta concepción se lleva a cabo. La investigación que hemos realizado ha mostrado cómo los deportistas sienten rechazo hacia esa explotación comercial de los deportes de naturaleza y de la propia naturaleza, considerando este hecho como una desvirtualización del sentido idealista que tales deportistas le otorgan a su actividad y el medio en el que la desarrollan.

Deportista 2: Estamos hablando un poco de turismo, que no es lo que hacemos nosotros... Normalmente son turistas no deportistas los que van alli el fin de semana. Mucha de la gente que va a andar o hacer montaña yo creo que al final hace muchas cosas y lo combina con un poquito de andar... Te vas al bosque a dar un paseo y no ves a nadie, y luego llegas al pueblo y está plagado.

(Grupo de discusión. Deportistas. Córdoba).

Así pues, podemos afirmar que las políticas de desarrollo rural contribuyen a la difusión de estos deportes, pero sólo entre un grupo social muy concreto, que no es el de los deportistas, sino en exclusiva los turistas que visitan el espacio rural. De acuerdo con ello, éstos (los turistas) serán percibidos como meros consumidores, en este caso consumidores de la experiencia rural. Y es que los programas de desarrollo rural promocionan estos deportes para favorecer la actividad de los nuevos empresarios en estos espacios, al convertirse en portadores de una imagen que es comercializada (la imagen rural) con el fin de atraer a unos visitantes que serán quienes la consuman. Se trata de un mercado, en este caso un mercado de ideas y experiencias, en el que participan fundamentalmente vendedores (empresarios) y consumidores (turistas). El resto de los actores estudiados en el marco de esta relación (la población local y los deportistas) tienen un menor peso, o, al menos, tienen menos ventajas para influir en la definición del territorio, sus usos y recursos. 


\subsection{La configuración de un nuevo marco de relaciones sociales en los espacios rurales}

El proceso de reestructuración rural ha ido configurando un nuevo marco de relaciones sociales en este espacio. El análisis de los deportes de naturaleza en el marco de este proceso así lo ha puesto de manifiesto. La promoción de estos deportes a través de los programas de desarrollo rural ha dado lugar a la entrada en escena de los empresarios del sector de turismo activo y de los turistas que visitan estas zonas, además de una mayor implicación (en un sentido muy heterogéneo) de la población local. Esta «incursión» de los empresarios y turistas, junto a la de otros actores como los técnicos relacionados con la gestión del territorio, ha dado lugar a un escenario en el que inevitablemente ha cambiado la interacción de los deportistas con el medio y ahora también con esos otros actores.

El marco de relaciones sociales surgido en el espacio rural, como consecuencia de la reestructuración, se caracteriza fundamentalmente por su carácter intrincado y conflictual. En efecto, la investigación ha puesto de manifiesto las tensiones existentes y las posiciones antagónicas que mantienen los distintos grupos de actores que tienen vinculación con las prácticas de los deportes de naturaleza en el proceso de la reestructuración rural. En torno a las distintas circunstancias que definen los intereses y motivaciones de cada uno de esos grupos de actores, que hemos denominado como sociales (la población local, los deportistas - y/o turistas - y los empresarios del sector del turismo activo) e institucionales (las agencias de desarrollo rural, las agencias de medio ambiente y los ayuntamientos y demás administraciones), en los tres territorios objeto de nuestro trabajo de campo (cada uno de los cuales caracterizado por un contexto socioeconómico diferente), quedan al descubierto multitud de colisiones que expresan la lucha simbólica que subyace a este proceso de reestructuración de los espacios rurales.

La conflictividad ha estado presente históricamente en las sociedades campesinas, siendo recogido en los trabajos realizados por los sociólogos dedicados a lo que entonces se conocía por estudios agrarios y campesinos. Sin embargo, la conflictividad que ha tenido lugar en el seno de las sociedades rurales, como consecuencia de los procesos de reestructuración rural-urbana y de las paradojas inducidas por los nuevos procesos productivos durante los años ochenta, ha sido objeto de una sociología que, ya sí, podríamos calificar de rural. En esta línea destacan los trabajos de Cloke y Thrift (1986), Lowe et. al. (1986), Robinson (1990), Camarero et. al., (1993), Woods (1998), Moyano y Paniagua (1998), González Fernández (2002), Oliva y Camarero (2003) y Moyano (2006), entre otros. En la relación que hemos venido analizando en este artículo, el estudio del conflicto ha suscitado menos trabajos, siendo pocos los autores que lo han abordado (González Fernández, 2002; Moyano, Garrido y Moscoso, 2004; González Fernández y Moscoso, 2006; Moscoso y Moyano, 2006).

Entre quienes han mostrado interés por las nuevas contingencias emergentes 
en el espacio rural, merece ser reconocida la contribución de Camarero et. al (1993) a la clasificación de los ejes de colisión: «el eje de la producción (generado por las diferentes reconversiones, la desagrarización, la desindustrialización...), el de la planificación (favorecido por una ordenación rural hecha «desde afuera» tanto cuando se orienta al desarrollo - parques naturales, pantanos...-, como cuando trata de ubicar los no-recursos - polígonos de tiro, centrales nucleares - ) y el de la convivencia (derivada de la presión que ejerce la progresiva heterogeneidad de los grupos que confluyen en los escenarios locales -inmigrantes, nuevos residentes-)» (op. cit Oliva y Camarero, 2003: 108).

En el trabajo en el que nos apoyamos, teníamos la convicción de que cualquier contingencia experimentada en la práctica de los deportes de naturaleza es debida a esa heterogeneidad identificada en torno a los sentidos y los usos del lugar en el espacio rural. El modo como el espacio es sentido y representado por la población local, los deportistas y los empresarios de turismo activo, y sobre cómo se desea hacer uso de ese espacio, entre estos actores y también entre los actores institucionales (que tienen un peso decisivo en la planificación de sus usos), son, sin duda, los dos elementos esenciales para interpretar esas contingencias.

En esta relación consideramos que los conflictos que se producen son de dos tipos, o tienen lugar a dos niveles: simbólicos (motivados por los diferentes estilos de vida de los deportistas, los empresarios y la población local; los desiguales sistemas de valores culturales con los que se identifican...) y materiales (las distintas maneras de entender el uso y explotación del espacio, o sea, los diversos intereses que distancian a estos grupos de actores en torno al fenómeno específico de los deportes de naturaleza, y las estrategias que emplean para ponerlos en práctica), ambos estrechamente relacionados e imbricados.

El nuevo escenario que se dibuja tiene como punto de partida la definición vertical (top-down) del territorio por medio de las directrices que llegan desde instancias superiores, esa poderosa maquinaria burocrática que dictamina el futuro de estos territorios (los programas de desarrollo rural, los planes de ordenación del territorio, las políticas de conservación y protección de la naturaleza); algo que estaría en contra del enfoque ascendente del que presumen quienes diseñan y gestionan las políticas de desarrollo rural.

Deportista 5: Yo creo que a las delegaciones de medio ambiente se les ha dado mucha autoridad y han hecho de esa autoridad autoritarismo. Entonces, muchas veces, sin haber hecho unos planes serios de uso y gestión de los espacios naturales, han hecho lo más fácil, que es prohibir. Es decir, «¿Esto cómo lo solucionamos? Prohibiendo». Y yo creo que ésa no es la solución. Hay que hacer unos estudios. Y yo creo que no lo hacen así, porque hay muchas contradicciones en materia de restricción entre unos espacios y otros, porque depende del delegado de medio ambiente de cada zona, de los intereses políticos

(Grupo de discusión. Deportistas. Córdoba). 
Esa apropiación de los significados sociales y los usos materiales del espacio rural que supone la reestructuración es lógico que genere un escenario conflictual, puesto que da lugar a un marco de competencia por adquirir «legitimidad» (es decir, influencia política, económica y social) en el diseño de la nueva ordenación del territorio. En otras palabras, los distintos actores tratan de posicionarse estratégicamente para adquirir capacidad de decisión a través de los órganos intermedios de participación social y política (ayuntamientos, asociaciones de empresarios, grupos de desarrollo rural, sindicatos, etc.). Así, por ejemplo, aquellos grupos de población a los que les interesa estos espacios por razones diferentes de los turistas (por ejemplo, los deportistas), experimentarán un agravio comparativo frente a esos turistas y los empresarios de turismo activo, bien por encontrarse limitados en el desarrollo de sus actividades, o bien por sentirse en desventaja de oportunidades, en términos de expectativas, frente a aquellos otros, que ven favorecidos sus intereses.

Deportista 5: Esa es una de las competencias más desleales que tenemos los clubes y particulares. $O$ sea, yo estuve el otro día haciendo el barranco de Río Verde. Mira, para conseguir un permiso para hacer Río Verde te las ves y te las deseas. Y ahora, sin embargo, tú vas a Río Verde y te encuentras cantidad de gente con empresas de multiaventura. Yo comprendo que a la gente del lugar hay que apoyarla para que cree sus empresas y explote sus recursos. Ahora, lo que tú no puedes es fastidiar a otra gente que vamos por nuestra cuenta o que tenemos unas instituciones que son los clubes, otra serie de intereses totalmente diferentes, pues claro, a nosotros los clubes no nos interesa a nivel económico, sino a nivel humano, a nivel ambiental, como quieras llamarlo. $Y$, sin embargo, nos estamos encontrando que las empresas de multiaventura tienen todas las facilidades y los clubes o los particulares ninguna. Al final es que te aburres

(Grupo de discusión. Deportistas. Córdoba).

Todo ello generará numerosos conflictos entre los deportistas y los demás actores, porque la realización de su actividad responde exclusivamente a razones de carácter moral o idealistas.

Deportista 1: Yo no concibo la vida sin hacer montaña. Pa mí es mi forma de vida. Yo es que el tiempo que tengo es pa ir al campo, que es el eje de mi vida

(Grupo de discusión. Deportistas. Jaén).

Deportista 1: A mí me interesa concretamente hacer deporte, digamos la motivación principal, y al mismo tiempo divertirme, entretenerme, conocer distintas sierras de Andalucía, porque con el club vamos a otros sitios... Fundamentalmente eso: el hacer el deporte que más me gusta, que más se adapta a mi situación, a mi edad...

Deportista2: hacer deporte, pero también evadirme, desconectar de la gente, del trabajo...

(Grupo de discusión. Deportistas. Córdoba). 
Para entender esta valoración quizá habría que realizar, además, una matización de interés, cual es la relación que han mantenido tradicionalmente los deportistas con este medio. Efectivamente, la práctica de deportes como el montañismo, como se sabe, parte de un origen muy antiguo. Un indicador de esta histórica relación es el hecho de que algunas conocidas sociedades de excursionistas y senderistas de nuestro país se crearon entre los años sesenta y setenta del siglo XIX. Por lo tanto, estos deportistas han construido lazos (simbólicos y materiales) muy estrechos con el espacio natural, o sea, han ejercido los mismos sistemas de apropiación simbólica y material sobre este espacio que otros grupos sociales (como los pastores, agricultores y ganaderos) desde tiempos muy remotos. Ello les induce a reclamar un papel más destacado en la ordenación de estos espacios.

\section{DISCUSIÓN}

La investigación ha tratado de obtener evidencias con el fin de explicar el proceso por el cual la emergencia de un nuevo modelo de economía rural y ordenación del territorio ha alterado las tradicionales concepciones del espacio y el uso de los recursos y, con ello, las relaciones entre los actores sociales, políticos y económicos. Para ello, hemos centrado nuestro análisis en un doble nivel: el nivel simbólico y el nivel material. El primer nivel de análisis (simbólico) ha revelado la existencia de una desigual concepción del espacio entre los distintos actores estudiados y, en particular, en relación a la capacidad del espacio rural para el desarrollo de los deportes de naturaleza. Se ha observado el predominio de dos concepciones generales en este sentido: una de carácter más económica y otra de carácter más ambiental. La primera se encuentra extendida entre la población local y los empresarios (también entre parte de los actores institucionales, si bien no los incluimos junto a los otros por no haber sido objeto del trabajo de campo) y se concreta en una visión del espacio rural en términos estrictamente económicos. El territorio rural es entendido exclusivamente como un espacio susceptible de generar actividad económica. En cambio, desde la concepción más ambiental, el territorio es visto como un lugar de interés para la realización de actividades no productivas, de esparcimiento y recreación, actividades dirigidas a la satisfacción de necesidades físicas y morales.

El segundo nivel de análisis (material) ha servido para constatar con mayor claridad la concepción simbólica del espacio. En este sentido, hemos observado cómo quienes comparten una visión más material del espacio rural conciben los deportes de naturaleza como un simple medio para ampliar el elenco de actividades económicas que se desarrollan en el territorio, por pensar que pueden contribuir a la creación de empleo y la obtención de rentas. Por tanto, entre quienes así piensan, los deportes de naturaleza representan únicamente una actividad económica y sus practicantes simples turistas o consumidores. Éstos entienden que 
el espacio rural debe ofrecer formas de explotación diferentes a las tradicionales actividades productivas (la agricultura, la ganadería...). En otras palabras, comparten una visión posproductivista del territorio, una visión que suele estar muy influida por las políticas de desarrollo rural. En el lado opuesto de este nivel se encuentran quienes conciben el espacio rural desde una concepción ambiental, los usuarios o turistas deportivos. Estos mantienen una posición exclusivamente moral respecto al uso del territorio, la práctica de los deportes de naturaleza.

Lo interesante de este grupo es que manifiesta curiosamente una relativa desvinculación (al menos entre una parte importante de estos deportistas) con el espacio en el que practican su actividad. El nexo que les une a este espacio es la necesidad moral de practicar unos determinados deportes que encuentran en él un lugar privilegiado para su realización. El resultado de esta diversificación de concepciones que pululan en el espacio rural es la proliferación de nuevos conflictos simbólicos y materiales en el territorio.

La conclusión que se puede extraer de este doble análisis (simbólico y material) es que todos los actores analizados comparten un espacio físico, que es el espacio rural, si bien no comparten «lugares» comunes - entendidos éstos como espacios construidos socialmente. Todos ellos coinciden en un espacio, pero no tienen nada que ver los unos con los otros. Ni a los locales les interesan los deportes de naturaleza, ni a los empresarios les interesan los deportistas puesto que, como actividad económica, sus clientes estarán representados por otro tipo de perfil (los turistas) - , ni los deportistas tienen un vínculo especialmente sólido con el territorio, porque lo que les motiva es practicar deportes de naturaleza. Todo esto explica el hecho de que, ante el proceso de la reestructuración rural, que implica esencialmente una nueva ordenación del territorio algo que podemos entender desde un punto de vista económico y político, con todo lo que ello conlleva-, nadie esté contento, suscitando ello múltiples conflictos.

Por lo tanto, el estudio demuestra que el análisis de este tipo de actividades (el turismo activo y los deportes de naturaleza) no puede concretarse en escudriñar los posibles datos tangibles que puedan existir sobre infraestructuras, empresas, oferta o demanda, porque, como se ha demostrado aquí, existen aspectos complejos de este fenómeno, en definitiva de la realidad social, que han de tratarse con otro tipo de aproximaciones que conjuguen adecuadamente el marco analítico con la investigación empírica. A su vez, más allá de esta evidencia sobre esta actividad, la investigación nos muestra que la reestructuración del espacio rural, en algunos casos y sentidos, más que una solución a los problemas del mundo rural, provee nuevas problemas difíciles de resolver sin vertebrar adecuadamente instrumentos de interlocución en los que tengan representación todos los actores del territorio, los nuevos y, por supuesto, los tradicionales. 


\section{BIBLIOGRAFÍA}

Augé, M. (1998): El viaje imposible. El turismo y sus imágenes, Barcelona, Gedisa.

BERgER, P. y T. LuCKMANn (1984): La construcción social de la realidad, Madrid. Amorrortu.

Blanchard, K. y Cheska, A. (1986): Antropología del Deporte, Barcelona, Bellaterra.

Camarero Rioja, L., V. J. Mazariegos y F. Rodríguez (1993): «Los campos de conflictividad en la España Rural», Documentación Social, 90, pp. 181-192.

Cloke, P. y THRIFT, N. (1986): «Intra class conflict in rural areas», Journal of Rural Studies, 3, pp. 321-333.

CoRCufF, P. (1998): Las nuevas sociologías, Madrid, Alianza.

DíAz Del Moral, J. (1979): Historia de las agitaciones campesinas andaluzas, Madrid, Alianza Editorial.

FEIXA, C. (1995): «La aventura imaginaria. Una visión antropológica de las actividades físicas de aventura en la naturaleza», Apunts: Educación física y Deportes, 41, pp. 36-43.

GonZÁlez Fernández, M. (2002): Sociología y ruralidades. La construcción social del desarrollo rural en el Valle de Liébana, Madrid, MAPYA.

GonZÁlez FernÁndeZ, M. y D. Moscoso (2006): «Hacia un sistema deportivo integrado y sostenible. La interlocución y la prevención en el proceso de instauración del deporte en los espacios naturales y las zonas rurales», en Culturas deportivas y valores sociales, Madrid, Librerías Esteban Sanz, pp. 569-586.

GuAY, D. (1993): La culture sportive, París, Presses Universitaires de France.

HoBsBAwn, E. (1978): «Bandolerismo social», en Rebelión campesina y cambio social, Barcelona, Crítica, pp.192-213.

Lowe, P., Cox, G., MacEwan, M., O'Riordan, T. y Winter, M. (1986): Countryside conflicts: the politics of framing, forestry and conservation, Aldershot, Gower.

Marsden, T., S. Whatmore y P. Lowe (1990): Rural Restructuring. Global Processes and their Responses, Londres, David Fulton Publishers.

Mardien, T., J. Murdoch, P. Lowe, R. Munton y A. Flynn (1993): Constructing the Countryside, Londres, UCL Press.

Moscoso, D. (2010): Deporte, Territorio y Desarrollo Rural en Andalucía, Madrid, Ministerio de Medio Ambiente y del Medio Rural y Marino.

- (2006): «La sociología del deporte en España. Estado de la cuestión», Revista Internacional de Sociología, 45, pp.177-204.

Moscoso, D. y E. Moyano (2006), Deporte y desarrollo rural, Sevilla, Instituto Andaluz del Deporte.

MOYANO, E. (1984): Corporatismo y agricultura. Asociaciones profesionales y articulación de intereses en la agricultura española, Madrid, MAPYA.

Moyano, E. y A. Paniagua (1998): «Agricultura, Espacios Rurales y Medio Ambiente», Revista Internacional de Sociología, 19-20, pp. 127-152.

- (2006): «Agricultura y mundo rural en España. Reflexiones para impulsar una política agraria y rural», Documento de su Comparecencia en la Comisión de Agricultura, Pesca y Alimentación del Senado, Madrid, el 28 de noviembre.

MoyAno, E., F. GARRIDO y D. Moscoso (2004): «Los campos conflictuales emergentes en torno a las prácticas deportivas, turísticas y medioambientales en los espacios naturales y las zonas rurales. Estudio de un caso», en Ocio, Turismo y Deporte en España, Santiago de Compostela, Edicións Tórculo, pp. 497-516 
Oliva, J. y L. CAMARERo Rioja (2003): Paisajes sociales y metáforas del lugar. Una reflexión sobre la ruralidad itinerante en Navarra, Pamplona, Universidad de Navarra.

PéreZ Yruela, M., J. Ma. Sumpsi, I. Bardají y Ma . M. Jiménez Guerrero (2000): La nueva concepción del desarrollo rural: Estudio de casos, Madrid, Consejo Superior de Investigaciones Científicas (CSIC).

RAFFESTin, C. (1995): «De la nature aux images de la nature», Espaces et Societés, 8283, pp.257-267.

RELPH, E. (1976): Place and placelessness, Londres, Pion.

RiverA, Ma. J. (2008): La ciudad inventada, Pamplona, Universidad Pública de Navarra.

RoberTs, L. y D. Hall (Compl.) (2001): Rural Tourism and Recreation: Principles to Practice, Wallingford, CABI Publishing.

Robinson, G. M. (1990): Conflict and change in the countryside, Londres, Bellhaven Press.

SÁNCHEZ, R. (1997): «Los usos sociales del riesgo: el deporte de aventura como configurador de una ética de la contingencia», en La actividad física y el deporte en un contexto democrático (1976-1996), Madrid, Librerías Esteban Sanz, pp. 21-53

Sevilla GuZmán, E. (1979): La evolución del campesinado en España, Barcelona. Península.

- (1997): «Los marcos teóricos del pensamiento social agrario», en Agricultura y sociedad en la España contemporánea, Madrid, CIS y Ministerio de Agricultura, Pesca y Alimentación, pp. 25-69

URrY, J. (1995): Consuming places, Londres, Routledge.

Walter, E.V. (1998): Placeways: A theory of the human environment, Chapel Hill. University of North Carolina Press.

Woods, J. (1998): «Researching rural conflicts: hunting, local politics and actornetworks», Journal of Rural Studies, 14, pp.321-340.

WoLF, E. (1979): Las luchas campesinas del siglo XX, México D.C., Siglo XXI editores. 


\section{ANEXO 1. DISEÑO MUESTRAL DEL TRABAJO DE CAMPO}

Tabla. 1. Grupo de Discusión Sierra de Segura

\begin{tabular}{|c|l|c|c|c|c|c|}
\hline Entrevista & $\begin{array}{c}\text { Características } \\
\text { informante }\end{array}$ & $\begin{array}{c}\text { Practicante } \\
\text { deportivo o } \\
\text { no }\end{array}$ & $\begin{array}{c}\text { Trayectoria } \\
\text { migratoria }\end{array}$ & Sexo & Edad & Municipio \\
\hline GD-1(1) & $\begin{array}{l}\text { Camarera en cam- } \\
\text { ping y técnico de } \\
\text { CAFDN }\end{array}$ & No & Local & Mujer & 23 & Siles \\
\hline GD-1(2) & $\begin{array}{l}\text { Gerente Empresa } \\
\text { Agroalimentaria }\end{array}$ & No & No Residente & Mujer & 29 & $\begin{array}{c}\text { Solana de } \\
\text { Torralba }\end{array}$ \\
\hline GD-1(3) & $\begin{array}{l}\text { Profesor de Prima- } \\
\text { ria, espe-cialidad } \\
\text { Educación Física }\end{array}$ & Sí & $\begin{array}{c}\text { Nuevo } \\
\text { Residente }\end{array}$ & Hombre & 33 & $\begin{array}{c}\text { Puerta de } \\
\text { Segura }\end{array}$ \\
\hline GD-1(4) & $\begin{array}{l}\text { Gerente Cooperati- } \\
\text { va Aceite }\end{array}$ & No & Local & Hombre & 32 & Orcera \\
\hline
\end{tabular}

Tabla 2. Grupo de Discusión Sierra Nevada (Barranco de Poqueira)

\begin{tabular}{|c|c|c|c|c|c|c|}
\hline Entrevista & $\begin{array}{l}\text { Características } \\
\text { informante }\end{array}$ & $\begin{array}{l}\text { Practicante } \\
\text { deportivo o } \\
\text { no }\end{array}$ & $\begin{array}{l}\text { Trayectoria } \\
\text { migratoria }\end{array}$ & Sexo & Edad & Municipio \\
\hline GD-2(1) & $\begin{array}{c}\text { Gerente Empresa } \\
\text { de Deportes de } \\
\text { Aventura } \\
\text { Nevadensis }\end{array}$ & Sí & $\begin{array}{c}\text { Nuevo } \\
\text { Residente }\end{array}$ & Hombre & 44 & Pampaneira \\
\hline GD-2(2) & $\begin{array}{l}\text { Empleada Hotel } \\
\text { Los Llanos }\end{array}$ & No & Local & Mujer & 25 & Capileira \\
\hline GD-2(3) & $\begin{array}{l}\text { Propietaria Hotel } \\
\text { Ruta Mulhacén }\end{array}$ & No & Local & Mujer & 51 & Pampaneira \\
\hline GD-2(4) & $\begin{array}{c}\text { Empleada Servicio } \\
\text { de Guías de } \\
\text { Naturaleza del } \\
\text { Parque Nacional } \\
\text { de Sierra Nevada }\end{array}$ & No & Local & Mujer & 44 & Pampaneira \\
\hline GD-2(5) & $\begin{array}{l}\text { Gerente Refugio de } \\
\text { Montaña Barranco } \\
\text { de Poqueira }\end{array}$ & Sí & $\begin{array}{c}\text { Nuevo } \\
\text { Residente }\end{array}$ & Hombre & 37 & Capileira \\
\hline
\end{tabular}

EMPIRIA. Revista de Metodología de Ciencias Sociales. N. ${ }^{\circ}$ 22, julio-diciembre, 2011, pp. 43-66. 
Tabla 3. Grupo de Discusión Jaén

\begin{tabular}{|c|c|c|c|c|c|c|}
\hline Entrevista & $\begin{array}{l}\text { Características } \\
\text { informante }\end{array}$ & $\begin{array}{l}\text { Principal } \\
\text { práctica de- } \\
\text { portiva }\end{array}$ & $\begin{array}{l}\text { Nivel de } \\
\text { práctica }\end{array}$ & Sexo & Edad & Municipio \\
\hline GD-4(1) & $\begin{array}{l}\text { Empleado en em- } \\
\text { presa Farmacéutica }\end{array}$ & Escalada & $\begin{array}{c}\text { Deportista } \\
\text { habitual }\end{array}$ & Mujer & 31 & Jaén \\
\hline GD-4(2) & $\begin{array}{l}\text { Enfermera, miem- } \\
\text { bro de club de } \\
\text { montaña y de la } \\
\text { Asamblea de la Fe- } \\
\text { deración Andaluza } \\
\text { de Montañismo }\end{array}$ & $\begin{array}{l}\text { Escalada y } \\
\text { alpinismo }\end{array}$ & $\begin{array}{c}\text { Deportista } \\
\text { habitual }\end{array}$ & Mujer & 29 & Jaén \\
\hline GD-4(3) & Ama de casa & $\begin{array}{l}\text { Senderismo y } \\
\text { alpinismo }\end{array}$ & $\begin{array}{c}\text { Deportista } \\
\text { habitual }\end{array}$ & Mujer & 39 & Jaén \\
\hline GD-4(4) & Estudiante & $\begin{array}{l}\text { Escalada, } \\
\text { senderismo, } \\
\text { alpinismo }\end{array}$ & $\begin{array}{c}\text { Deportista } \\
\text { habitual }\end{array}$ & Mujer & 28 & Jaén \\
\hline
\end{tabular}

Tabla 4. Grupo de Discusión Córdoba

\begin{tabular}{|c|c|c|c|c|c|c|}
\hline Entrevista & $\begin{array}{c}\text { Características } \\
\text { informante }\end{array}$ & $\begin{array}{l}\text { Principal } \\
\text { práctica de- } \\
\text { portiva }\end{array}$ & $\begin{array}{l}\text { Nivel de } \\
\text { práctica }\end{array}$ & Sexo & Edad & Municipio \\
\hline GD-3(1) & $\begin{array}{l}\text { Funcionario de la } \\
\text { Adm. Central de } \\
\text { Estado y miembro } \\
\text { de club de montaña }\end{array}$ & senderismo & $\begin{array}{l}\text { Deportista de } \\
\text { fin de semana } \\
\text { y vacaciones }\end{array}$ & Hombre & 59 & Córdoba \\
\hline GD-3(2) & $\begin{array}{l}\text { Empleada Hacien- } \\
\text { da y miembro de } \\
\text { club de montaña }\end{array}$ & senderismo & $\begin{array}{l}\text { Deportista de } \\
\text { fin de semana } \\
\text { y vacaciones }\end{array}$ & Mujer & 55 & Córdoba \\
\hline GD-3(3) & $\begin{array}{l}\text { Investigador Cien- } \\
\text { tífico, miembro de } \\
\text { club de montaña y } \\
\text { de plataforma pro- } \\
\text { caminos (en contra } \\
\text { de las alambradas) }\end{array}$ & $\begin{array}{c}\text { senderismo y } \\
\text { media } \\
\text { montaña }\end{array}$ & $\begin{array}{l}\text { Deportista de } \\
\text { fin de semana } \\
\text { y vacaciones }\end{array}$ & Hombre & 35 & Córdoba \\
\hline GD-3(4) & $\begin{array}{l}\text { Enfermera y miem- } \\
\text { bro club de monta- } \\
\text { ña }\end{array}$ & $\begin{array}{c}\text { senderismo y } \\
\text { media } \\
\text { montaña }\end{array}$ & $\begin{array}{l}\text { Deportista de } \\
\text { fin de semana } \\
\text { y vacaciones }\end{array}$ & Mujer & 36 & Córdoba \\
\hline GD-3(5) & $\begin{array}{l}\text { Profesor Secundaria } \\
\text { y fundador de varios } \\
\text { clubes deportivos, } \\
\text { entre ellos uno de de- } \\
\text { portes de naturaleza }\end{array}$ & $\begin{array}{c}\text { senderismo, } \\
\text { BTT y } \\
\text { espeleología }\end{array}$ & $\begin{array}{c}\text { Deportista } \\
\text { habitual }\end{array}$ & Hombre & 51 & Puente Genil \\
\hline
\end{tabular}

EMPIRIA. Revista de Metodología de Ciencias Sociales. N. ${ }^{\circ}$ 22, julio-diciembre, 2011, pp. 43-66. ISSN: 1139-5737 
Tabla 5. Entrevistas Individuales Semiestructuradas

\begin{tabular}{|c|c|c|c|c|c|c|}
\hline Entrevista & $\begin{array}{l}\text { Características } \\
\text { informante }\end{array}$ & $\begin{array}{l}\text { Practicante } \\
\text { deportivo o } \\
\text { no }\end{array}$ & $\begin{array}{l}\text { Trayectoria } \\
\text { migratoria }\end{array}$ & Sexo & Edad & Municipio \\
\hline \multicolumn{7}{|c|}{ Sierra de Segura } \\
\hline E-1 & $\begin{array}{l}\text { Celador en el SAS } \\
\text { y Educador Am- } \\
\text { biental }\end{array}$ & Sí & $\begin{array}{c}\text { Nuevo } \\
\text { Residente }\end{array}$ & Hombre & 51 & Orcera \\
\hline \multicolumn{7}{|c|}{ Las Alpujarras - Sierra Nevada (Barranco de Poqueira) } \\
\hline E-2 & $\begin{array}{l}\text { Propietario Empre- } \\
\text { sa de Turismo Ac- } \\
\text { tivo, especializado } \\
\text { en caballos y presi- } \\
\text { dente de AJETREA } \\
\text { - Asoc. Granadina } \\
\text { de Empresarios de } \\
\text { Turismo Rural y } \\
\text { Ecuestre de Anda- } \\
\text { lucía }\end{array}$ & Sí & $\begin{array}{l}\text { Nuevo } \\
\text { Residente }\end{array}$ & Hombre & 53 & Bubión \\
\hline E-3 & $\begin{array}{c}\text { Gerente Empresa } \\
\text { «Aventura Horizon- } \\
\text { tal» Parapente }\end{array}$ & Sí & $\begin{array}{c}\text { Nuevo } \\
\text { Residente }\end{array}$ & Hombre & 38 & Bubión \\
\hline \multicolumn{7}{|c|}{ Subbética Cordobesa } \\
\hline E-4 & $\begin{array}{l}\text { Coordinador CE- } \\
\text { GESTUR (Centro } \\
\text { de Gestión de Turis- } \\
\text { mo Rural de Córdo- } \\
\text { ba) }\end{array}$ & No & Local & Hombre & 29 & Lucena \\
\hline E-5 & $\begin{array}{c}\text { Co-Propietario Em- } \\
\text { presa de Deportes } \\
\text { de Aventura ALÚA }\end{array}$ & Sí & $\begin{array}{c}\text { Nuevo } \\
\text { Residente }\end{array}$ & Hombre & 30 & Zuheros \\
\hline E-6 & $\begin{array}{l}\text { Profesor Enseñanza } \\
\text { Secundaria Modulo } \\
\text { de Conducción de } \\
\text { Actividades en la } \\
\text { Naturaleza }\end{array}$ & Sí & Local & Hombre & 42 & Baena \\
\hline E-7 & $\begin{array}{l}\text { Co-Propietario Em- } \\
\text { presa de Turismo } \\
\text { Activo INTERNA- } \\
\text { TURA }\end{array}$ & Sí & $\begin{array}{l}\text { Nuevo Resi- } \\
\text { dente }\end{array}$ & Hombre & 35 & Espiel \\
\hline E-8 & $\begin{array}{l}\text { Presidente del Club } \\
\text { Náutico de Bélmez }\end{array}$ & Sí & Local & Hombre & 45 & Belmez \\
\hline
\end{tabular}

EMPIRIA. Revista de Metodología de Ciencias Sociales. N. ${ }^{\circ}$ 22, julio-diciembre, 2011, pp. 43-66. 